\title{
User-friendly Method and Skew Removal in NIRF
}

\section{T.R. Neelakantan}

\begin{abstract}
National Institute Ranking Framework (NIRF) initiative of Government of India is becoming popular among students. NIRF changed ranking methods in the past and stabilizing. This paper presents some analyses and suggestions based on the 4th edition of annual ranks released in April 2019. Unlike many private ranking systems, NIRF ranking is performed by the Government of India and it analyses a lot of data. However, if the facilities of presenting data in the user-friendly format are provided, many students and others may benefit a lot. Further, some of the parameters are less required by students and has skew. Suggestions are given to improve NIRF so that more students and others will get benefitted.
\end{abstract}

Keywords : Higher Education, National Institute Ranking Framework, Rank.

\section{INTRODUCTION}

\section{$\mathrm{N}_{\text {ational Institute Ranking Framework (NIRF) }}$} (https://www.nirfindia.org/Home) initiative of India was started ranking the institutes from the year 2016. The annual ranking of institutes is released in the month of April, every year. Ranks are provided in an increasing number of disciplines, and the methodology is being refined. NIRF ranks are becoming popular among students. However, compared to reputed international private ranking systems, such as QS (www.topuniversities.com/subject-rankings/2019) and THE (www.timeshighereducation.com/world-university-rankings) rankings, NIRF is not user-friendly. NIRF gives overall rank, overall score and scores in different parameters for each institute. NIRF allows the users to sort the institutes based on rank, state and city. NIRF does not permit to sort based on parameters such as 'teaching, learning, and resources'. A total score or overall rank based on all the parameters is not useful to all [1]. Hence, to improving NIRF is essential for sustainability. The objectives of this paper are (a) to highlight the need for more user-friendly data presentation requirement in NIRF ranks and (b) to explain the skew present in the parameter 'perception'.

\section{USER-FRIENDLY DATA PRESENTATION}

NIRF states that it gives yearly scorecard of the institutes to the stakeholders. NIRF uses different weights for different parameters. For example, research is given more importance to universities compared to the colleges. However, these weights are not essentially valid for all. For example, in

Revised Manuscript Received on December 13, 2019.

* Correspondence Author

T.R. Neelakantan*, Department of Civil Engineering, Kalasalingam Academy of Research and Education, 626126, India, neelakantan@klu.ac.in
Engineering ranking 'Research and Professional Practice' is given $30 \%$ weight. This $30 \%$ weight may be considered too high by a student aspiring to join B.Tech. programme in Computer Science to get a job after an undergraduate degree. However, that student may assume a weight of more than $10 \%$ for employment scope through the campus placement (graduation outcome $10 \%$ weight by NIRF). As of now, NIRF helps the users to shortlist the ranks based on state or cities by alphabetical order. Instead, if provision for selecting a region covering a few states (example: Tamilnadu, Karnataka, Kerala, Andrapradesh, and Telangana in a region) is provided in the user interface it will be of great use to many.

\section{COMPARISON OF INSTITUTES BASED ON PARAMETERS}

The weights given by NIRF or the overall score may not be suitable to all types of students. It has been demonstrated using NIRF 2019 Engineering scores of four Deemed Universities in Tamilnadu, namely VIT (Vellore Institute of Technology), SRM (SRM Institute of Science and Technology), SASTRA (Shanmugha Art, Science, Technology and Research Academy) and KARE (Kalasalingam Academy of Research and Education). The scores of these institutes in each parameter and the overall score are presented in table 1. An aspiring student, who has a job ready from his family company, wishes to get an undergraduate degree in Computer Science and Engineering. His interest is in learning, and among the five parameters used by NIRF, his interest is mainly on the first parameter (Teaching, Learning \& Resources), and he may prefer KARE due to the highest score of $67.60 \%$ in this parameter. If a student also looks for placement support, among the five parameters used by NIRF, his interest will be mainly on first (Teaching, Learning \& Resources) and third (Graduation Outcomes). Further, if he gives equal weight to these parameters, he will choose SASTRA due to the highest score of $(65.79+64.66) / 2=65.23 \%$. Similarly, if a student aspiring for the Ph.D. programme is likely to concentrate on the second parameter (Research and Professional Practice), and may select VIT as the highest score in this parameter is $57.34 \%$. Suppose, if the seat availability at VIT is doubtful, he may next consider SRM as it is in the second rank in this parameter. Though all the data are available on the NIRF website, if a student can compare and the data as shown in table 1 , it will be convenient for the student. It is to be recalled that the online vendors of mobile phones provide such 'compare' options based on price and specifications. 


\section{User-friendly Method and Skew Removal in NIRF}

Similarly, a comparison of the tuition fee and score in the parameters of institutions will be useful to the students.

Table- I: NIRF 2019 engineering scores of some of the deemed universities in Tamilnadu

\begin{tabular}{|l|c|c|c|c|c|}
\hline Parameters & $\begin{array}{c}\text { NIRF } \\
\text { weight }\end{array}$ & VIT & SRM & SASTRA & KARE \\
\hline $\begin{array}{l}\text { Teaching, Learning } \\
\text { \& Resources (TLR) }\end{array}$ & 0.3 & 54.65 & 59.85 & 65.79 & $\mathbf{6 7 . 6 0}$ \\
\hline $\begin{array}{l}\text { Research and } \\
\text { Professional } \\
\text { Practice (RPC) }\end{array}$ & 0.3 & $\mathbf{5 7 . 3 4}$ & 33.40 & 31.04 & 14.08 \\
\hline $\begin{array}{l}\text { Graduation } \\
\text { Outcomes (GO) }\end{array}$ & 0.2 & 63.57 & 63.04 & $\mathbf{6 4 . 6 6}$ & 53.96 \\
\hline $\begin{array}{l}\text { Outreach and } \\
\text { Inclusivity (OI) }\end{array}$ & 0.1 & 56.69 & $\mathbf{6 2 . 1 8}$ & 56.42 & 55.70 \\
\hline Perception (PR) & 0.1 & $\mathbf{4 4 . 8 1}$ & 21.53 & 12.14 & 3.95 \\
\hline Overall score & & 56.46 & 48.95 & 48.83 & 41.26 \\
\hline \multicolumn{1}{|c|}{ Rank } & & 18 & 36 & 38 & 61 \\
\hline
\end{tabular}

Tables 2, 3, and 4 are drawn out from the 2019 NIRF Engineering scores by manual collection. Since all the data are available in the NIRF scores, only a software tool is required to pull out the data in the desired form. This form of data will be desired by the students as explained above. Especially the parameter 'Outreach and Inclusivity' may not be significant criteria for the majority of the students in selecting the institutes, whereas this is important for the government to provide the opportunity to all the citizens. Suppose, if a state or region is suffering 'outreach and inclusivity' score by all the institutes, then the governments may try to correct this through special programmes and facilities. For this, the ranks by 'outreach and inclusivity' score will be of great use. Thus, while undergraduate students may show interest in parameters 1 and 3, post-graduate and $\mathrm{Ph}$.D. students show interest in parameter 2, the government agencies with social service agenda show interest in parameter 4 . The parameter 5 depends majorly on the location, size, age, and advertising. To be more student-friendly, NIRF may also give the fee structure of different programmes.

Table- II: Ranking of engineering institutes in Tamilnadu as per NIRF score in teaching, learning and resources (TLR)

\begin{tabular}{|l|l|l|}
\hline Rank & Institution Name & $\begin{array}{l}\text { Score out } \\
\text { of } 100\end{array}$ \\
\hline 1 & Indian Institute of Technology Madras & 93.55 \\
\hline 2 & Sri Sivasubramaniya Nadar College of Engineering & 69.13 \\
\hline 3 & PSG College of Technology & 68.97 \\
\hline 4 & National Institute of Technology, Tiruchirappalli & 68.36 \\
\hline 5 & $\begin{array}{l}\text { Kalasalingam Academy of Research and Higher } \\
\text { Education }\end{array}$ & 67.6 \\
\hline 6 & $\begin{array}{l}\text { Shanmugha Arts Science Technology \& Research } \\
\text { Academy }\end{array}$ & 65.79 \\
\hline 7 & Coimbatore Institute of Technology & 63.46 \\
\hline 8 & Anna University & 63.17 \\
\hline 9 & Thiagarajar College of Engineering & 61.68 \\
\hline 10 & Sathyabama Institute of Science and Technology & 61.42 \\
\hline 11 & Kumaraguru College of Technology & 61.09 \\
\hline 12 & Hindustan Institute of Technology and Science & 59.96 \\
\hline 13 & SRM Institute of Science and Technology & 59.85 \\
\hline 14 & Kongu Engineering College & 58.18 \\
\hline 15 & $\begin{array}{l}\text { Sri Krishna College of Engineering and } \\
\text { Technology }\end{array}$ & 57.92 \\
\hline 16 & Bannari Amman Institute of Technology & 56.28 \\
\hline 17 & Karunya Institute of Technology and Sciences & 55.46 \\
\hline & \multicolumn{2}{|c|}{ Kageng } \\
\hline
\end{tabular}

$18 \quad$ Vellore Institute of Technology 54.65

19 Vel Tech Rangarajan Dr. Sagunthala R \& D 53.49 Institute of Science and Technology

\begin{tabular}{|l|l|l}
\hline 20 & Government College of Technology, Coimbatore & 52.33 \\
\hline
\end{tabular}

\begin{tabular}{|l|l|l}
\hline 21 & Mepco Schlenk Engineering College & 51.38 \\
\hline
\end{tabular}

Table- III: Ranking of engineering institutes in Tamilnadu as per NIRF score in graduate outcome (GO)

\begin{tabular}{|l|l|l|}
\hline Rank & Institution Name & $\begin{array}{l}\text { Score out } \\
\text { of } 100\end{array}$ \\
\hline 1 & Indian Institute of Technology Madras & 84.36 \\
\hline 2 & National Institute of Technology, Tiruchirappalli & 72.76 \\
\hline 3 & $\begin{array}{l}\text { Shanmugha Arts Science Technology \& Research } \\
\text { Academy }\end{array}$ & 64.66 \\
\hline 4 & Sri Sivasubramaniya Nadar College of Engineering & 63.63 \\
\hline 5 & Vellore Institute of Technology & 63.57 \\
\hline 6 & Sri Krishna College of Engineering and Technology & 63.51 \\
\hline 7 & Anna University & 63.24 \\
\hline 8 & SRM Institute of Science and Technology & 63.04 \\
\hline 9 & Sathyabama Institute of Science and Technology & 62.26 \\
\hline 10 & Kumaraguru College of Technology & 57.4 \\
\hline 11 & Thiagarajar College of Engineering & 56.74 \\
\hline 12 & $\begin{array}{l}\text { Kalasalingam Academy of Research and Higher } \\
\text { Education }\end{array}$ & 53.96 \\
\hline 13 & Bannari Amman Institute of Technology & 53.94 \\
\hline 14 & PSG College of Technology & 53.37 \\
\hline 15 & Government College of Technology, Coimbatore & 51.77 \\
\hline 16 & Mepco Schlenk Engineering College & 51.01 \\
\hline 17 & Coimbatore Institute of Technology & 50.95 \\
\hline 18 & Karunya Institute of Technology and Sciences & 49.4 \\
\hline 19 & Kongu Engineering College & 48.37 \\
\hline 20 & Hindustan Institute of Technology and Science & 47.83 \\
\hline 21 & $\begin{array}{l}\text { Vel Tech Rangarajan Dr. Sagunthala R \& D Institute of } \\
\text { Science and Technology }\end{array}$ & 37.45 \\
\hline & & \\
\hline & & \\
\hline & & \\
\hline
\end{tabular}

Table- IV: Ranking of engineering institutes in Tamilnadu as per NIRF score in outreach and inclusivity (OI)

\begin{tabular}{|l|l|l|}
\hline Rank & Institution Name & $\begin{array}{l}\text { Score out } \\
\text { of } 100\end{array}$ \\
\hline 1 & Indian Institute of Technology Madras & 63.99 \\
\hline 2 & National Institute of Technology Tiruchirappalli & 62.2 \\
\hline 3 & SRM Institute of Science and Technology & 62.18 \\
\hline 4 & Sathyabama Institute of Science and Technology & 61.93 \\
\hline 5 & $\begin{array}{l}\text { Vel Tech Rangarajan Dr. Sagunthala R \& D Institute } \\
\text { of Science and Technology }\end{array}$ & 57.83 \\
\hline 6 & Vellore Institute of Technology & 56.69 \\
\hline 7 & $\begin{array}{l}\text { Shanmugha Arts Science Technology \& Research } \\
\text { Academy }\end{array}$ & 56.42 \\
\hline 8 & $\begin{array}{l}\text { Kalasalingam Academy of Research and Higher } \\
\text { Education }\end{array}$ & 55.7 \\
\hline 9 & Karunya Institute of Technology and Sciences & 55.47 \\
\hline 10 & Hindustan Institute of Technology and Science & 53.23 \\
\hline 11 & Sri Sivasubramaniya Nadar College of Engineering & 52.66 \\
\hline 12 & Anna University & 52.66 \\
\hline 13 & Government College of Technology & 51.89 \\
\hline 14 & Thiagarajar College of Engineering & 49.23 \\
\hline 15 & PSG College of Technology & 48.73 \\
\hline 16 & Mepco Schlenk Engineering College & 48.21 \\
\hline 17 & Sri Krishna College of Engineering and Technology & 46.64 \\
\hline 18 & Coimbatore Institute of Technology & 46.48 \\
\hline 19 & Kongu Engineering College & 45.7 \\
\hline 20 & Kumaraguru College of Technology & 45.64 \\
\hline 21 & Bannari Amman Institute of Technology & 44.92 \\
\hline & & \\
\hline 14 & \\
\hline
\end{tabular}

\section{RESEARCH FUND ISSUE}

One of the often debated item in institute ranking is the research grants component. NIRF gives significant weight to grants received by the institutes.

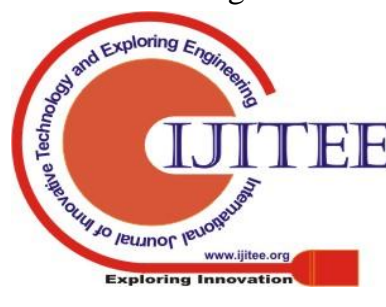


Research outputs are majorly depending on the research budget. There are arguments that institutions with high research budget have an unfair advantage in rankings [2]. However, in NIRF, support by government agencies is given significant weight. Agency A provides financial support for research at institutions run by it and for other institutions also. Agency B provides financial support for research at institutions run by it alone. While evaluating the research performance, is it fair to ignore the grants received from $B$ ? NIRF ignores the research grant by the trust which runs the institute, while research grants from Government agencies are considered. Government institutes are run by Governments and it is natural that the Government has to provide more funding for creating laboratory facilities, salary, maintenance, etc. Similarly, private institutes also spend significant fund from their trusts. For a higher education institute, major expenses are related to research. Governments also support private institutions to some extent as they do good for society. However, Governments' support for their own institutions and private institutions cannot be compared. The issue with NIRF may be accessing reliable data on funding by private trusts. Instead of ignoring, mechanism of reliably assessing the private funding is to be developed and incorporated. NIRF may take steps to avoid being quoted for 'What is incorporated into the rankings is, what is measurable, not what is valid' (quoted in [3]). To be fair, if trust funds to private institutes are not considered, on the same measure, government funds to government institutes should also not be considered. Further, ranking based on efficiency is always better than ranking based on input. Though not immediately, gradually NIRF may move towards the return on the research grants (publications and patterns per investment of Rs one million). Otherwise, low-efficiency government institutes will get an undue advantage. It is proven many times in many fields that the private management is more efficient (output per unit investment or benefit-cost ratio) than government managed ones. Hence, efficiency or benefit-cost analysis is to be used in NIRF for research investment component. This will guide the PG and Ph.D. students and fund-granting agencies properly. All stakeholders know that the funding from government agencies to Government run institutions are generally more, and ranking based on the fund received by government agencies makes a bias. Hence, the classification of institutes into 'Government', 'Government aided' and 'Private' will be of more use to the students.

\section{CORRELATION BETWEEN 'PERCEPTION' AND 'RESEARCH AND PROFESSIONAL PRACTICE'}

The correlations among the five parameters used by NIRF for the top 21 engineering institutes in Tamilnadu (which are listed in top 100 in India - 2019 ranking) are presented in table 5. Similarly, the correlations among the five parameters used by NIRF for the top 100 engineering institutes in India in 2019 ranking are presented in table 6 . These tables indicate that the 'Perception' has a correlation of 0.78 or 0.77 with 'Research and Professional Practice', which is reasonably high compared to other correlations. This reveals that those participated in perception responded by the influence of research outcomes. This reveals that even though $30 \%$ weight

is given to research, perception is also mostly influenced by research. Hence, the weight for research can be construed as more than $30 \%$. The very low correlations of 0.30 and 0.15 between 'perception' and 'Outreach and inclusivity' in Tamilnadu state and India indicate the low participation of perception participants who work for outreach and inclusivity in institutes. This either shows a bias or overall less interest in 'outreach and inclusivity'. NIRF may develop methods to increase the number of responses from this sector in the perception survey.

Table- V: Correlation among parameters among the top 21 institutes in Tamilnadu

\begin{tabular}{|l|l|l|l|l|l|}
\hline Top 21 institutes in Tamilnadu \\
\hline Correlation & TLR & RPC & GO & OI & PR \\
\hline TLR & 1.00 & & & & \\
\hline RPC & 0.63 & 1.00 & & & \\
\hline GO & 0.72 & 0.73 & 1.00 & & \\
\hline OI & 0.41 & 0.68 & 0.49 & 1.00 & \\
\hline PR & 0.66 & $\mathbf{0 . 7 8}$ & 0.64 & 0.30 & 1.00 \\
\hline
\end{tabular}

Table- VI: Correlation among parameters among top 100 institutes in India

\begin{tabular}{|l|l|l|l|l|l|}
\hline Correlation & TLR & RPC & GO & OI & PR \\
\hline TLR & 1.00 & & & & \\
\hline RPC & 0.53 & 1.00 & & & \\
\hline GO & 0.29 & 0.55 & 1.00 & & \\
\hline OI & 0.32 & 0.03 & 0.24 & 1.00 & \\
\hline PR & 0.56 & $\mathbf{0 . 7 7}$ & 0.60 & 0.15 & 1.00 \\
\hline
\end{tabular}

\section{SKEW IN 'PERCEPTION'}

The range of values of different parameters shown in table 7 indicates the improper normalization as the ranges are not well distributed among the institutions. When the parameters 'Research and Professional Practice' and 'Perception' are almost ranging between 0 and 100, the parameter 'Teaching, Learning Resources' minimums are 51.38 and 41.83 for Tamilnadu and India respectively. Though the values are claimed to be awarded based on percentiles, it looks strange that even the top 100 institutions received a minimum score of as low as 1.63 in 'Perception', which means that the many of the 970 participated institutions have received zero or low values. This confirms the NIRF statement in their manual that that only reputed academicians and recruiters are requested for perception survey. For examples, if professors from IITs only are requested to participate in the perception survey, the probability of other institutes to get better perception is almost zero. There is a bias in the selection of respondents, and hence the results will also be biased. The issue of brain-drain from IITs is also to be considered. If the survey respondents are selected randomly covering academicians from all type of institutes, and all levels of recruiters, this skew may be avoided. It is fair to expect the minimum score of 'Perception' among the top 100 institutes be at least around 30, otherwise, the overall scores also become skewed.

Table- VII: Range of parameters in Tamilnadu and in India among Top 100 engineering institutes

\begin{tabular}{|l|l|l|l|l|l|l|}
\hline Level & TLR & RPC & GO & OI & PR \\
\hline Tamilnadu & Max & 93.55 & 92.39 & 84.36 & 63.99 & 100 \\
\hline
\end{tabular}




\begin{tabular}{|l|l|l|l|l|l|l|}
\hline & Min & 51.38 & 2.29 & 37.45 & 44.92 & 2.41 \\
\hline \multirow{2}{*}{ India } & Max & 93.55 & 96.18 & 89.84 & 68.5 & 100 \\
\cline { 2 - 7 } & Min & 41.83 & 2.16 & 5.46 & 32.1 & 1.63 \\
\hline
\end{tabular}

\section{CONCLUSION}

In this paper, from the results of NIRF 2019 for engineering, data have been shown to demonstrate the user-friendly presentation need in NIRF. Further, the correlation of the parameters 'Perception' with 'Research and Professional Practice' is shown from the data. Skew in perception is also highlighted from the 2019 data and the possible reason for that is explained along with remedies. Since NIRF methodology is improved every year for better sustainability, some suggestions for improvement in methodology and presentation are provided in this paper.

\section{REFERENCES}

1. G. Prathap, "Danger of a single score: NIRF rankings of colleges" Curr. Sci., 113(4), 550-553, 2017.

2. A. Gorobets, "Universities rankings: methodology should be improved" Curr. Sci., 114(2), 245, 2018.

3. L. Cremonini, D. Westerheijden, J. Enders, "Disseminating the right information to the right audience: cultural determinants in the use (and misuse) of rankings" High. Educ., 55, 373-385, 2008. DOI 10.1007/s10734-007-9062-8

\section{AUTHOR PROFILE}

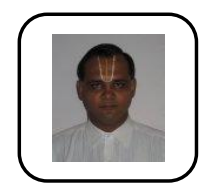

Dr. T.R. Neelakantan is a Senior Professor in Civil Engineering and Director - Accreditation and Ranking at Kalasalingam Academy of Research and Education, Tamilnadu. He obtained his Ph.D. degree in Civil Engineering from Anna University in the year 1998. His working experiences are from Anna University, IIT-Madras, SASTRA Deemed University and the University of Kentucky, Lexington, USA. He published more than 60 articles in reputed journals, and handled many government and private funded projects both in India and USA. 